\title{
Adolescente surdo e os conflitos da idade: o olhar da Psicologia
}

\author{
Marcia Cristina Lobo ${ }^{1}$
}

\begin{abstract}
RESUMO: O período da adolescência já é cercado por diversos estigmas e para um adolescente surdo não é diferente, principalmente uma vez constatando dificuldades na qualidade da comunicação durante a infância. Este trabalho analisa e compara as peculiaridades do desenvolvimento do adolescente surdo com o adolescente ouvinte na perspectiva da Psicologia. 0 estudo demonstra a importância da qualidade da comunicação dos pais para com seus filhos durante a fase da infância, a qual representa os primeiros aprendizados no que se referem aos valores, princípios, assim como o fortalecimento do laço familiar, sendo este de estrema significância no que tange a autoestima e a autoimagem de um indivíduo e consequentemente de suas futuras escolhas. E para o surdo, a adolescência como uma fase da vida de grande estima, uma vez que pode ser o seu período identificatório de maior importância para a fase seguinte e o restante de sua vida.
\end{abstract}

Palavras-chave: Adolescência. Cultura surda. Surdo. Adolescente surdo.

\section{Deaf adolescent and age conflicts: the look of Psychology}

\begin{abstract}
The adolescent period is already surrounded by several stigmas and for a deaf adolescent it is not different, especially once it has noticed difficulties in the quality of communication during childhood. This work analyzes and compares the peculiarities of the development of the deaf adolescent with the adolescent listener in the perspective of Psychology. The study demonstrates the importance of the quality of parents' communication to their children during the childhood phase, which represents the first learning in terms of values, principles, as well as the strengthening of the family bond. Which concerns the self-esteem and self-image of an individual and consequently of their future choices. And for the deaf, adolescence as a life stage of great esteem as it may be your most important identifying period for the next phase and the remainder of your life.
\end{abstract}

Keywords: Adolescence. Deaf culture. Deaf. Deaf teenager.

- Enviado em 08/08/2016

- Aprovado em 15/10/2016

\footnotetext{
${ }^{1}$ Graduada em Psicologia pela Pontifícia Universidade Católica do Paraná (PUCPR). Pós-graduanda em Educação Especial: Educação Bilíngue para Surdos - LIBRAS/ Língua Portuguesa pelo Instituto Paranaense de Ensino e Faculdade de Tecnologia América do Sul.Endereço eletrônico: marciac.lobo@hotmail.com
} 


\section{INTRODUÇÃo}

A adolescência é marcada por todo o seu enredamento em se caracterizar como uma fase de transição e modificações adversas, em um período transitório de latência em que este não se encontra nem nas regalias do mundo da infância e nem das vantagens da independência do mundo adulto. Fase esta também assinalada por grandes conflitos pessoais e para com o mundo que o cerca, no qual o jovem, muitas vezes, não consegue encontrar o seu lugar na sociedade e fica numa constante busca por outros caminhos por meio de grupos sociais de identificações. Com isso podemos aqui avaliar e refletir as possíveis problemáticas e especificidades para o adolescente surdo.

Supondo essas especificidades ao analisarmos que, entre as crianças surdas, $90 \%$ têm pais ouvintes, e a ausência de experiência com perda de audição faz com que esses pais enfrentem vários obstáculos em relação ao desenvolvimento dessa criança, sendo um deles a dificuldade de comunicação (ELEWEKE; RODDA 2000 p.145). Pensando na indispensabilidade da interação de um indivíduo para a formação da sua identidade, a comunicação entra aqui como uma ferramenta básica. E isso vai acontecer desde o nascimento com o meio em que este está inserido, a partir do qual constituirá não só sua identidade, como também sua inteligência e personalidade.

Com isso demonstra-se fundamental um aprofundamento cada vez maior do tema para uma maior compreensão dos desafios de um adolescente surdo durante sua vida. Tendo em vista esta perspectiva, este estudo destina-se a analisar as peculiaridades do desenvolvimento do adolescente surdo no olhar da Psicologia.

\section{ADOLESCÊNCIA E A FORMAÇÃO DA IDENTIDADE}

De acordo com o Estatuto da Criança e do Adolescente Lei 8.069/90, considera-se criança a pessoa até os doze anos de idade incompletos, e adolescente aquela entre doze e dezoito anos de idade. Porém sabe-se que a adolescência é um processo de transição entre a infância e a vida adulta, que não necessariamente segue a risca a idade determinada pelo Estatuto (BRASIL, 1990). 
A adolescência se inicia com as mudanças corporais da puberdade, período de transição entre a infância e a vida adulta, caracterizado pelos impulsos do desenvolvimento físico, mental, emocional, sexual e social. Erikson (1972) coloca como a tarefa mais importante da adolescência, a construção da identidade, a qual implica em definir quem a pessoa é, quais são seus valores e quais as direções que deseja seguir pela vida. 0 autor entende que identidade é uma concepção de si mesmo, composta de valores, crenças e metas com os quais o indivíduo está solidamente comprometido. Assim concorda Zacarés (1997) ao ressaltar que a identidade desenvolve-se durante todo o ciclo vital, mas é no período da adolescência que ocorrem as transformações mais significantes. A preocupação com a identidade torna-se mais consciente e intensa por vários fatores, entre os quais o autor destaca a "maturação biológica, o desenvolvimento cognitivo alcançado e as demandas sociais para comportamentos mais responsáveis".

Quando crianças, vivemos um mundo de sonhos e fantasias e temos de maior referência os nossos pais ou responsáveis. É comum vermos os filhos imitando os pais, usando suas roupas, buscando falar e se comportar de forma parecida. Os sonhos e valores dos pais tornam-se os dos filhos. Arón e Milicic (1994) enfatiza isso ao explicar que a família é um grupo primário. Secundário são os grupos de trabalho, estudo, instituições. Em todos eles, encontramos um lugar, um papel, uma forma de estar, que por sua vez constitui nossa maneira de ser. Nesse espaço desempenhamos nosso papel, segundo nossa história e as marcas que trazemos conosco. A criança nasce e entra num mundo socialmente dado, em nosso grupo primário temos um espaço que ocupamos com o único papel possível.

Já na adolescência, ao contrário da infância, o interesse dos jovens se desloca cada vez mais para atividades fora de casa, na convivência com os grupos de amigos e na busca de pertencimento, é comum inclusive, gostos, sonhos, desejos e perspectivas até mesmo contrárias das dos pais. Os autores Barbosa, Costa e Vieira (2008) comentam sobre a sensação que os pais podem sentir de seu filho adolescente não mais apreciar o convívio com a família, passando cada vez menos tempo em contato íntimo com os familiares. Tornam-se pensativos, silenciosos, secretos, não dão satisfações de seus atos, sendo impenetráveis em seu recolhimento, egocêntricos e indiferentes. Ser incompreendido pelos adultos é, ao mesmo tempo, o drama e o desejo do adolescente; queixa-se da incompreensão, mas alimenta uma 
secreta pretensão de ser um fato indecifrável para qualquer adulto; ele tanto se sente único, complexo e especial, como desamparado, confuso e só.

$\mathrm{Na}$ fase adulta é possível fazer suas escolhas de forma mais crítica e menos influenciável. E eis que muitas vezes pode se surpreender em não só continuar com as referencias atuais conseguidas na adolescência, mas voltar às referencias e valores da infância, anteriormente esquecidas ou ignoradas. Ao pensarmos neste momento como crucial na formação da identidade de um indivíduo, Kimmel e Weiner (1998) afirmam que, quanto mais desenvolvido o sentimento da própria identidade, mais o indivíduo valoriza o modo em que é parecido ou diferente dos demais e mais claramente reconhece suas limitações e habilidades. Quanto menos desenvolvida, mais o indivíduo necessita o apoio de opiniões externas para avaliar-se e compreende menos as pessoas como distintas.

Marcia (1966) apresenta duas dimensões essenciais na formação de qualquer identidade pelo adolescente: uma crise ou exploração e um comprometimento ou compromisso. Por crise ou exploração, o autor entende o período de tomada de decisão, quando antigos valores e antigas escolhas são reexaminados, podendo ser de forma tumultuada ou ocorrer gradualmente. Na dimensão comprometimento ou compromisso, o autor supõe que o indivíduo tenha realizado uma escolha relativamente firme, servindo como base ou guia para sua ação. 0 resultado desejado da exploração é o comprometimento com algum papel específico, alguma determinada ideologia. 0 comprometimento é medido pelo grau de investimento pessoal que o indivíduo expressa. Os compromissos correspondem às questões que o indivíduo mais valoriza e com as quais mais se preocupa, refletindo o sentimento de identidade pessoal.

\section{ADOLESCENTE SURDO E SUAS PARTICULARIDADES}

Considerar a adolescência no contexto da surdez implica a compreensão de que a surdez representa um fator de diferenciação nesse processo, desde que ao surdo seja possibilitado o progresso de seus potenciais. Tal como o momento da descoberta da surdez e os primeiros anos de vida, a adolescência é um momento de tensão, pois, nesse período, a surdez é novamente percebida em seus limites. Se já é difícil para todo adolescente aceitar as 
mudanças corporais típicas da puberdade, no caso do adolescente surdo, a tarefa é mais árdua, pois ele também tem que dar conta da falta de audição ou da dificuldade de falar (SHORN, 1997; VIROLE, 2001).

Para Behares (1993), a criança surda que nasce em um meio ouvinte enfrenta, desde o nascimento, uma rede de construções identificatórias, prefiguradas pelas expectativas de seus pais, os quais, é natural, desejam que ela também seja ouvinte. Dessa forma, o processo de socialização da criança surda com pais ouvintes é, muitas vezes, conflitante desde o início. As autoras Negrelli e Marcon (2006) acrescentam ainda que com a pouca assistência ao seu desenvolvimento, os estigmas da deficiência e a baixa valorização social desses indivíduos afeta diretamente a família que, geralmente, se sente despreparada e com dificuldade em aceitar a chegada de uma criança surda.

O que nos faz refletir aqui quais as possíveis consequências na adolescência e mesmo na fase adulta já que, por exemplo, para Arón e Milicic (1994) a família é vista como a maior agência de socialização em nossa sociedade e constitui para a criança o primeiro ambiente significado. Nessa perspectiva, os pais e os irmãos constituem modelos muitos poderosos e significativos para criança. A influência que a vida familiar exerce sobre as crianças não se restringe apenas a lhe oferecer modelos de comportamento, já que ela também conforma sua conduta social através das diversas práticas de disciplina. 0 estilo familiar, os padrões de punição, o sistema de crença e os valores são elementos que tem impacto importante no desenvolvimento das habilidades sociais.

Lane (1995) observa que há uma diferença entre crianças surdas de pais surdos e crianças surdas de pais ouvintes, na sua interação com o mundo e na forma de aprendizagem. Os pais surdos que tem filhos surdos sabem como educa-los desde que nascem, sabem se comunicar com a Língua de Sinais, sabem usar jogos visuais e gestuais. Isso não acontece com os filhos surdos de pais ouvintes. Os pais ouvintes quando tomam conhecimento da surdez do filho, em geral, nunca conheceram um surdo e não sabem que existe uma língua de sinais natural dos surdos. Esse choque de cultura de línguas, imediatamente já diminui a comunicação entre pais e filhos.

Vale ressaltar que embora haja muitas limitações é através da relação de maternagem, mesmo que o surdo não tenha acesso à língua oral - língua de sua família - a mãe vai falar por ele, vai 
interpretar por ele. Isso vai auxiliar para que ele possa ter acesso, mesmo que bastante precário, a uma identificação com a família. Vai ser através dos traços visuais que o surdo vai absorvendo e selecionando traços que possibilitam que ele se identifique com seus familiares (MARTINS 2003)

Tais informações vêm de encontro com Behares e Peluso (1997) quando explicam sobre os "sinais caseiros", estes utilizados quando os surdos não tem acesso à língua de sinais e estabelece estes com a família e em especial com a mãe, os quais podem durar por anos e/ou para sempre. Porém os autores ressaltam que ao não ter acesso a uma língua estruturada, a quantidade e a qualidade de informações e assuntos abordados são muito inferiores àqueles que os indivíduos ouvintes, em sua maioria, recebem e trocam. E comentam que os surdos, nestas condições, só conseguem expressar e compreender assuntos do aqui e agora. Para falar sobre situações passadas, lugares diferentes e, principalmente, sobre assuntos abstratos são quase impossíveis - se realmente não o for.

Quando filho surdo e pais ouvintes não compartilham uma língua em comum para que possam trocar experiências, para que possam compartilhar histórias familiares, para que possam orientar o filho nos valores da família, para que possam introduzir a cultura familiar, o que é repassado ao filho é muito reduzido e o que ele compreende também é limitado, comprometendo a identificação com a família de origem (MARTINS 2003).

Sabendo disso, os amigos e colegas surdos passam a exercer uma importante função na construção da identidade, pois permitem relações nas quais o adolescente surdo não será marcado pela falta e pela deficiência, como acontece, implícita ou explicitamente, com os ouvintes. Felipe e Monteiro (2005) afirmam que os surdos possuem "uma forma peculiar de apreender o mundo que gera valores, comportamento comum compartilhado e tradições sociointerativas. A esse modus vivendis dá-se o nome de Cultura Surda".

Então, o adolescente surdo filho de pais ouvintes precisa fazer uma negociação identidatária entre a cultura ouvinte - de seus pais e da sociedade mais ampla - e a comunidade surda (SOLÉ, 1998). Ainda para a autora, a adolescência, entendida como possibilidade de construção de um projeto de vida, implica a busca de outros referenciais identitários que possibilitem ao adolescente uma definição estável, mas não encerrada, de si mesmo. Nessa transição entre infância e idade adulta, os papéis ocupados pelo adolescente no 
meio familiar durante a infância serão revistos e ressignificados, ao mesmo tempo em que é importante haver uma procura de outros referenciais além da família. Por isso, a construção identidatária implica compartilhar significados públicos com determinados grupos.

A surdez e a privação da fala fragilizam os laços familiares durante a transmissão da cultura familiar, tendo como consequência uma impossibilidade de identificação com o nome da família à qual pertence. Quando os surdos se encontram com a língua de sinais e a comunidade surda, os pais ouvintes deixam de ser as referências de identificação para os adolescentes surdos. Os ensinamentos dos pais são substituídos pelos da comunidade surda, os valores dos pais pelos dos amigos surdos e inclusive suas crenças religiosas. Ao deparar com a comunidade surda, o surdo vê a possibilidade de alcançar a singularidade, pois encontra um grupo em que a diferença, marcada pela surdez, não é relevante, diminuindo o sentimento de ser diferente que sentia em relação à família de origem. Ingressa numa relação que acredita ser de igualdade, onde os ensinamentos paternos, os valores familiares são substituídos pelos da comunidade surda, onde há um rompimento com a tradição familiar (SOLÉ 1998).

O que podemos observar aqui é um movimento do adolescente surdo não muito diferente do adolescente ouvinte, pois este também, como explica Papalia, Olds e Feldman (2000) buscam amigos que tenham comportamento, maneira de pensar e agir parecidos com os seus, há um fortalecimento dos laços que os unem ao grupo, sobretudo através das relações de confiança, que muitas vezes não encontram no ambiente familiar, o que dificulta a relação e aprofunda o conflito com a família. Os autores comentam que em alguns casos esse processo é tão intenso que essa aproximação não é tão fácil uma vez que a separação do grupo se torna algo impossível. 0 adolescente se sente mais pertencente ao grupo de afinidades do que ao grupo familiar.

Ressaltando, porém como característico do adolescente surdo e dessemelhante do adolescente ouvinte, a frágil relação com os pais, estes ouvintes, obtida na infância e as consequências uma vez chegada à fase adulta, observando a infância como um período crucial da vida, pois é nela que estabelecemos confiança em nós mesmos e nos outros, que aprendemos sobre limites e aspectos sociais, e também de que forma podemos e devemos nos relacionar com o mundo. 
Segundo Romanelli (1997) a família corresponde a um lugar privilegiado de afeto, no qual estão inseridos relacionamentos íntimos, expressão de emoções e de sentimentos. Portanto, pode-se dizer que é no interior da família que o indivíduo mantém seus primeiros relacionamentos interpessoais com pessoas significativas, estabelecendo trocas emocionais que funcionam como um suporte afetivo importante quando os indivíduos atingem a idade adulta. Estas trocas emocionais estabelecidas ao longo da vida são essenciais para o desenvolvimento dos indivíduos e para a aquisição de condições físicas e mentais centrais para cada etapa do desenvolvimento psicológico.

\section{ADOLESCENTE SURDO E A PSICOLOGIA}

A família representa o espaço onde a criança dá seus primeiros passos e tem suas primeiras experiências de relacionamentos interpessoais e as interações perturbadas podem representar uma referência confusa para a criança surda em desenvolvimento. Para Erikson (1972), se os laços formados durante esse período não forem de confiança e autonomia, a crise da identidade na adolescência culmina em uma confusão de papéis que pode ser angustiante e dificultar o relacionamento afetivo saudável do indivíduo com sua família e, posteriormente, em qualquer instância em que ele se relacione.

De acordo com Oliveira e Lima (2010), a deficiência auditiva pode gerar disfunções emocionais, dificuldade de aprendizagem, alterações de fala, dificuldades profissionais, descontentamento e isolamento.

Li e Prevatt (2010) verificaram possíveis diferenças em níveis e tipos de medos e ansiedade vivenciados em crianças e adolescentes surdos ou com dificuldade auditiva comparando com uma amostra de ouvintes jovens. Os resultados apontaram que as crianças e adolescentes surdos apresentaram níveis significativamente mais altos de medo e ansiedade geral, medo do desconhecido, medo de lesões e de pequenos animais, medos de procedimentos médicos e dificuldade de concentração em comparação com os participantes ouvintes. 
É possível sustentar a premissa de perdas psicológicas para com a surdez, mas estas não seriam inerentes diretamente à surdez, e sim geradas por conflitos sociais, ocupacionais, pedagógicos e, ou seja, em relação com a sociedade, e não simplesmente pelo fator orgânico de não poder ouvir (CARDOSO; CAPITÃO, 2007). Os autores também ressaltam a importância de pensar o surdo na perspectiva da alteridade, com o conceito de diferença ao invés de deficiência como primordial para que seja possível compreender como se deu seu desenvolvimento, como foi sua vida enquanto criança, mais dentro de casa, e, posteriormente, no adentrar da vida escolar e, por fim, a composição de um adulto, autônomo e surdo, sendo preciso considerar veementemente o contexto.

Ao pensar na profissão da Psicologia e suas possíveis contribuições para com a surdez, Bisol, Simoni e Sperb (2008) comentam que atualmente estudos realizados sobre produções científicas de profissionais da Psicologia demonstram que a concepção desta área de atuação sobre as pessoas surdas está mudando consideravelmente, pois ao contrário do modelo anterior, que mantinha uma visão clínico-terapêutica da surdez, a concepção atual está mais voltada para o entendimento socioantropológico, que considera a pessoa surda como integrante de uma cultura distinta e com uma forma linguística diferenciada da maioria populacional, o que interfere diretamente na maneira como se compreende tal público e como relacionar-se com ele, distanciando-se da busca diagnóstica e reabilitadora. Em vez de deficiência, entende-se a surdez como diferença.

\section{CONSIDERAÇÕES FINAIS}

Como Psicóloga na área clínica vejo dia após dia em consultório adolescentes trazendo seus conflitos internos, seus questionamentos, e suas dificuldades de relacionamento. Percebo em suas falas, nas suas expressões e angústias, o quão tudo parece tão grande, intenso e grave nessa complexa fase da vida. Discordo do pensamento errôneo de que adolescentes só querem chamar atenção, só estão revoltados ou mimados. Os sentimentos lá dentro são reais, e se há sofrimento, este é real também.

Durante o artigo fica evidente a importância de uma estrutura familiar fortalecida, uma infância bem amparada e da comunicação como forma de se passar valores, de poderem se 
expressar verdadeiramente, e não só superficialmente como pode acontecer nos casos de pais ouvintes com filhos surdos, uma vez que desconhecem o mundo da surdez e às vezes demoram em buscar a melhor forma de se comunicarem.

A adolescência já e uma fase naturalmente de afastamento do adolescente do meio familiar, a comunicação já fica truncada, mas ao chegar à fase adulta, uma vez que seus valores estão bem enraizados em uma infância saudável, este poderá fazer novas escolhas de forma mais consciente e madura.

Costumo utilizar de uma metáfora de autor desconhecido para pais de adolescentes, estes comumente cheios de dúvidas com relação ao novo comportamento do filho e até mesmo acompanhados de sentimentos de culpa. A metáfora explica o ciclo de vida como uma forma de preenchermos três baús. 0 primeiro baú, representado pela infância, é preenchido pelos ensinamentos e exemplos dos pais, estes considerados como a maior referência. Na adolescência teria um segundo baú, este preenchido por outros aprendizados mais direcionados há outras referências, uma vez que o mundo do adolescente foi se ampliando na medida da busca de novas identificações para a formação da sua identidade. Quando chega a fase adulta, o não mais tão jovem, dessa vez mais maduro e crítico com suas escolhas, poderá ponderar entre os dois primeiros baús e assim preencher o terceiro e último baú, fazendo as escolhas do que quer carregar consigo entre suas referências durante a infância e a adolescência.

A dificuldade encontrada na comunicação de pais ouvintes para com seu filho surdo, principalmente na fase da infância, fez-me questionar a qualidade do preenchimento deste primeiro baú, assim como o que foi exposto durante o artigo a respeito de uma comunicação limitada e reduzida. Ao contrário do que pode acontecer na adolescência, um segundo baú muito mais recheado, principalmente ao se deparar com a comunidade surda e com uma possibilidade de comunicação, compreensão e expressão mais intensa e aprofundada.

Assim podemos concluir com este artigo, ao analisarmos as peculiaridades do adolescente surdo, como uma fase da vida de grande importância para este indivíduo, uma vez que pode ser o seu período identificatório de maior importância para a fase seguinte e o restante de sua vida. 


\section{REFERÊNCIAS}

ARÓN, A. M; MILICIC, N. Viver com os outros: Programa de desenvolvimento de habilidades sociais. Editoril Psy II, 1994.

BARBOSA, S. M; COSTA, P. N. P.; VIEIRA, N. F. C. Estágios de Mudança dos Pais nas Conversas com os Filhos sobre Prevenção HIV/AIDS. Rev Latino-am Enfermagem. v. 16, n. 6, nov./dez, 2008.

BEHARES, L. E. Nuevas corrientes en la educación del sordo: de los enfoques clínicos a los culturales. Cadernos de Educação Especial da Universidade Federal de Santa Maria, 1(4), 20$53,1993$.

BEHARES, L. E; PELUSO, L. A língua materna dos surdos. Revista Espaço, Rio de Janeiro: INES, n. 6, p. 40-48, mar,1997.

BISOL, C. A; SIMIONI, J; SPERB, T. Contribuições da psicologia Brasileira para o estudo da surdez. Psicol. Reflex. Crit. [online], 2008.

BRASIL. Estatuto da criança e do adolescente: Lei federal no 8069, de 13 de julho de 1990. Rio de Janeiro: Imprensa Oficial, 2002.

CARDOSO, L. M; CAPITÃO, C. G. Avaliação psicológica de crianças surdas pelo Teste das Pirâmides Coloridas de Pfister. PsicoUSF, dez., vol. 12, no 2, p. 135- 144, 2007.

ELEWEKE, J; RODDA, M. Factors contributing to parents' selection of a communication mode to use with their deaf children. American Annals of the Deaf, 145(4), 375-383, 2000.

ERIKSON, E. H. Identidade, juventude e crise. Tradução de Álvaro Cabral. Rio de Janeiro: Zahar, 1972

FELIPE, T; MONTEIRO, M. LIBRAS em contexto: curso básico; livro do professor. 4. ed. Rio de Janeiro: LIBRAS Editora Gráfica, 2005.

KIMMEL, D; WEINER, I. (1998). La adolescencia: una transición del desarrollo. Barcelona: Ariel

LANE, H. A Máscara da Benevolência: a comunidade surda amordaçada. Lisboa: Horizontes Pedagógicos, 1995.

LI, H; PREVATT, F. Deaf and hard of hearing children and adolescents in China: their fears and anxieties. American Annals of the deaf, 155 (4), 458-466, 2010.

MARCIA, J; E. Development and validation of ego-identity status. Journal of Personality and Social Psychology, 3, 551-558, 1966. 
MARTINS, R. V. Língua de sinais e subjetividade. Porto Alegre. 170 f. Tese (Doutorado em Psicologia) - Instituto de Psicologia, Pontifícia Universidade Católica do Rio Grande do Sul, 2003

NEGRELLI, M. E. D; MARCON, S. S. Família e criança surda. Ciência, Cuidado e Saúde, Maringá, v.5, n.1, p. 98-107, jan./abr, 2006

OLIVEIRA, M. A. O; LIMA, R. F. A Língua Brasileira de Sinais (LIBRAS) na formação de professores. (Trabalho de conclusão do curso de Pós-Graduação Libras e Educação de Surdos), 2010.

PAPALIA, D. E; OLDS, S. W; FELDMAN, R. D. Desenvolvimento humano. 7 ed. Porto Alegre: Artmed, 2000.

ROMANELLI, G. Famílias de classes populares: socialização e identidade masculina. Cadernos de Pesquisa NEP, 1-2, 25-34, 1997.

SOLÉ, M. C. P. A clínica psicanalítica em língua de sinais: reflexões de uma analista ouvinte sobre essa prática. Correio da Associação psicanalítica de Porto Alegre (APPOA), Porto Alegre, ano IX, n.88, p.50-59, mar, 2001.

SHORN, M. E. El niño y el adolescente sordo: reflexiones psicoanalíticas. Buenos Aires: Lugar Editora, 1997.

VIROLE, B. Développement psychologique de l'enfant sourd: Moments critiques. 2001.

ZACARÉS, J. J. El desarrollo de la identidad adolescente desde el paradigma de los status de identidad del ego: cuestiones críticas. Comunicação apresentada no VI Congreso de la Infancia y de la Adolescencia, Oviedo, Espanha, 1997. 